\title{
Breast cancer precursors: lessons learned from molecular genetics
}

\author{
Hans-Peter Sinn
}

Received: 18 December 2008 / Accepted: 19 December 2008 / Published online: 13 January 2009

(C) Springer-Verlag 2009

Keywords Breast cancer $\cdot$ Molecular genetics $\cdot$ DCIS

The question how breast cancer evolves has been subject to many studies, but many details of the molecular pathogenesis of sporadic type breast cancer are still unknown; this applies both to hormone-dependent and hormone-independent breast cancer. However, histopathologic, genetic, and epidemiological studies have provided good evidence that almost all types of breast cancer are preceded by noninvasive precursor lesions [ductal carcinoma in situ (DCIS), lobular carcinoma in situ (LCIS)] that share many molecular similarities with invasive breast cancer $[1,2]$. The most important contributions have come from studies involving comparative genomic hybridization (CGH), particularly with modifications that allow the use of paraffin-embedded material [3]. CGH analysis of DCIS has demonstrated a large number of gains at 1q, 5p, 6q, 8q, 17q, 19q, 20p, 20q, and $X \mathrm{q}$ and losses of 2q, 5q, 6q, 8p, 9p, 11q, 13q, 14q, 16q, $17 p$, and $22 q[4-6]$, and these changes are similar to invasive ductal carcinomas that are associated with large DCIS [7]. In fact, no genetic alterations specific for DCIS or invasive breast cancer were detected so far [8]. Interestingly, these DCIS lesions closely reflect the molecular subtypes of breast cancer that they precede or are associated with [9]. This has led to the distinction of two major molecular pathways in DCIS [4, 10]: a low-grade pathway that leads to the development of mostly hormone-

H.-P. Sinn $(\bowtie)$

Sektion für Gynäkologische Pathologie, Pathologisches Institut, Im Neuenheimer Feld 220,

69120 Heidelberg, Germany

e-mail: peter_sinn@med.uni-heidelberg.de receptor-positive tumors and a high-grade pathway. There is strong molecular evidence that precursor lesions are committed by their molecular profile to progress either to low- or high-grade carcinomas. This was repeatedly shown by comparison of molecular alterations at the genetic level of invasive breast carcinoma with adjacent ductal or lobular carcinoma in situ [4, 11], and among other evidence [12], this has lead to the hypothesis that breast cancer in general is not one but many different diseases, even at the precursor stage [13].

Today, it is evident that the neoplastic process begins earlier than at the DCIS stage, but which histological lesions are directly involved in this process is not being fully understood. More than 30 years ago, Jensen et al. [14] described a continuum of morphologic changes linking hyperplastic and metaplastic lesions including usual ductal hyperplasia (UDH) to DCIS and invasive breast cancer. This model was derived from morphologic observations on the similarity and topographic relationship of non-neoplastic lesions to in situ neoplasia and has become textbook knowledge since. Only in 2001 was it shown that this multistep model does not apply because the earliest lesion, $\mathrm{UDH}$, is genetically unaltered and characterized by another cytokeratin profile than DCIS [15]. Therefore, UDH is usually not neoplastic in nature [8] and cannot be regarded as an immediate precursor of DCIS. In recent years, a new hypothesis has been put forward about what constitutes the immediate precursor for DCIS. As illustrated in Fig. 1, there is now compelling evidence that columnar cell lesions are the "missing" link between normal breast tissue and DCIS in the low-grade pathway [16, 17], and by clonality analysis of mitochondrial DNA, this was proven at least for invasive tubular carcinoma [18]. In this issue of J Mol Med, Gao et al. [19] provide further evidence to the concept of 
Fig. 1 Stepwise tumor progression leading to invasive ductal carcinoma (low-grade pathway). This is a modified WellingsJensen model showing linear progression from luminal cells within a terminal ductal lobular unit (TDLU) and blunt duct adenosis $(B D A)$ that may progress into flat epithelial atypia $(F E A)$ and atypical ductal hyperplasia $(A D H)$ into ductal carcinoma in situ (DCIS) and finally leading to invasive ductal carcinoma (IDC). The usual ductal hyperplasia $(U D H)$ and simple microcysts are not considered to belong to this pathway. The figure has been taken and slightly adapted from Lee et al. [17] with permission

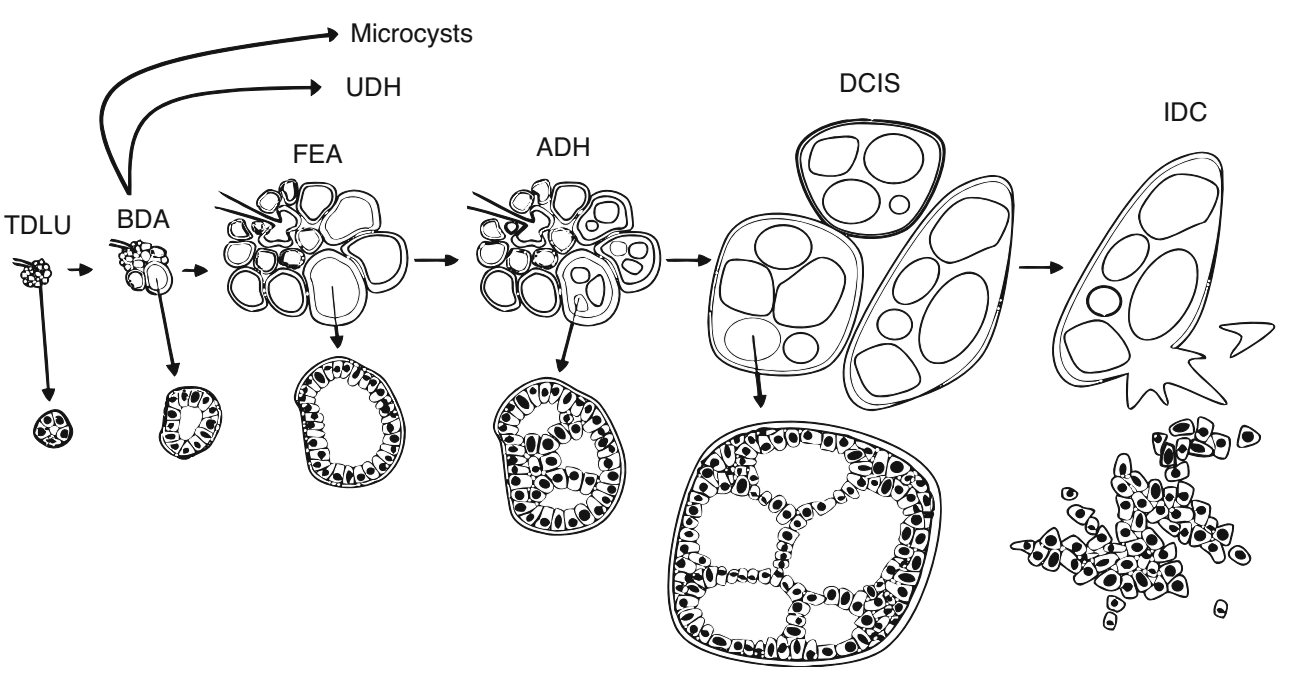

very early precursor lesions, with atypical ductal hyperplasia as the earliest neoplastic lesion that is related to DCIS.

In contrast to DCIS, LCIS or lobular neoplasia, as it is called nowadays, has generally been considered to be a mere risk factor for the later occurrence of ipsilateral or contralateral breast cancer [20]. The risk associated with LCIS is low, with the majority of carcinomas that are associated with LCIS occurring more than 10 years after the initial diagnosis of LCIS [21]. However, studies on the molecular genetics of LCIS [22, 23], clonality studies [11, 24] and morphologic evidence [25] indicate that LCIS is much more closely related to invasive lobular carcinoma and a direct precursor in a proportion of cases yet to be determined. Also, molecular genetic studies of LCIS studies have shown many similarities with low-grade DCIS, strengthening the view of LCIS being an immediate precursor lesion and placing LCIS in the low-grade pathway of breast cancer [26].

These insights on the molecular biology of breast cancer precursors have important implications for clinical practice. Firstly, the distinction between fully developed DCIS or LCIS and lesions previously regarded as atypical hyperplasia (atypical ductal hyperplasia, flat epithelial atypia, atypical lobular hyperplasia) is blurred [9]. Although the risk associated with the early precursor lesions is low, it is regarded as severe enough to recommend excision in most cases if found in core needle biopsy [27]. Secondly, the knowledge of low- and high-risk pathways allows for the identification of lesions with a higher probability of recurrence [28], and careful attention must be paid especially to these high-grade DCIS to ascertain the completeness of excision and rule out tumor invasion by the pathologist. Thirdly, the identification of atypical columnar cell lesions as the "missing link" in the multistep theory of the evolution of low-grade breast cancer [16, 29] has created much awareness to these lesions, and the correct management of these low-risk lesions in the breast has been subject to debate [30]. Taken together, only a broad concept of breast cancer precursors has been established today, and much remains to be learned with regard to the significance of individual genetic and epigenetic alterations, which may eventually lead to a more refined and clinically oriented classification of precursor lesions.

Acknowledgment This work has been funded in part by the University of Heidelberg, Frontier initiative with the project "Identification of methylated genes in preneoplastic mammary lesions as potential biomarkers and chemopreventive targets in invasive breast cancer."

\section{References}

1. Radford DM, Phillips NJ, Fair KL, Ritter JH, Holt M, DonisKeller H (1995) Allelic loss and the progression of breast cancer. Cancer Res 55:5180-5183

2. Fujii H, Szumel R, Marsh C, Zhou W, Gabrielson E (1996) Genetic progression, histological grade, and allelic loss in ductal carcinoma in situ of the breast. Cancer Res 56:5260-5265

3. Isola J, DeVries S, Chu L, Ghazvini S, Waldman F (1994) Analysis of changes in DNA sequence copy number by comparative genomic hybridization in archival paraffin-embedded tumor samples. Am J Pathol 145:1301-1308

4. Bürger H, Otterbach F, Simon R, Poremba C, Diallo R, Decker T, Riethdorf L, Brinkschmidt C, Dockhorn-Dworniczak B, Böcker W (1999) Comparative genomic hybridization of ductal carcinoma in situ of the breast-evidence of multiple genetic pathways. J Pathol 187:396-402

5. Waldman FM, DeVries S, Chew KL, Moore DH, Kerlikowske K, Ljung BM (2000) Chromosomal alterations in ductal carcinomas in situ and their in situ recurrences. J Natl Cancer Inst 92:313-320 
6. Kuukasjarvi T, Tanner M, Pennanen S, Karhu R, Kallioniemi OP, Isola J (1997) Genetic changes in intraductal breast cancer detected by comparative genomic hybridization. Am J Pathol 150:1465-1471

7. Aubele M, Mattis A, Zitzelsberger H, Walch A, Kremer M, Welzl G, Höfler H, Werner M (2000) Extensive ductal carcinoma In situ with small foci of invasive ductal carcinoma: evidence of genetic resemblance by CGH. Int J Cancer 85:82-86

8. Reis-Filho JS, Lakhani SR (2003) The diagnosis and management of pre-invasive breast disease: genetic alterations in pre-invasive lesions. Breast Cancer Res 5:313-319

9. Simpson PT, Reis-Filho JS, Gale T, Lakhani SR (2005) Molecular evolution of breast cancer. J Pathol 205:248-254

10. Roylance R, Gorman P, Harris W, Liebmann R, Barnes D, Hanby A, Sheer D (1999) Comparative genomic hybridization of breast tumors stratified by histological grade reveals new insights into the biological progression of breast cancer. Cancer Res 59:14331436

11. Hwang ES, Nyante SJ, Yi Chen Y, Moore D, DeVries S, Korkola JE, Esserman LJ, Waldman FM (2004) Clonality of lobular carcinoma in situ and synchronous invasive lobular carcinoma. Cancer 100:2562-2572

12. Arpino G, Laucirica R, Elledge RM (2005) Premalignant and in situ breast disease: biology and clinical implications. Ann Intern Med 143:446-457

13. Wiechmann L, Kuerer HM (2008) The molecular journey from ductal carcinoma in situ to invasive breast cancer. Cancer 112:2130-2142

14. Jensen HM, Rice JR, Wellings SR (1976) Preneoplastic lesions in the human breast. Science 191:295-297

15. Böcker W, Bürger H, Schmitz K, Ellis IA, van Diest PJ, Sinn HP, Geradts J, Diallo R, Poremba C, Herbst H (2001) Ductal epithelial proliferations of the breast: a biological continuum? Comparative genomic hybridization and high-molecular-weight cytokeratin expression patterns. J Pathol 195:415-421

16. Simpson PT, Gale T, Reis-Filho JS, Jones C, Parry S, Sloane JP, Hanby A, Pinder SE, Lee AH, Humphreys S, Ellis IO, Lakhani SR (2005) Columnar cell lesions of the breast: the missing link in breast cancer progression? A morphological and molecular analysis. Am J Surg Pathol 29:734-746

17. Lee S, Mohsin SK, Mao S, Hilsenbeck SG, Medina D, Allred DC (2006) Hormones, receptors, and growth in hyperplastic enlarged lobular units: early potential precursors of breast cancer. Breast Cancer Res 8:R6
18. Aulmann S, Elsawaf Z, Penzel R, Schirmacher P, Sinn HP (2008) Klonaler Zusammenhang flacher Epithelatypien und tubulärer Mammakarzinome. Pathologe 29(Suppl.2):353-356

19. Gao XN, Y, Wang, X; Wei, L; Lu, S (2009) Genetic changes at specific stages of breast cancer progression detected by comparative genomic hybridization. J Mol Med doi:10.1007/s00109-008-0408-1

20. Sinn HP, Helmchen B, Aulmann S (2006) Konzept und Problematik der lobulären Neoplasie. Pathologe 27:373-380

21. Rosen PP, Kosloff C, Lieberman PH, Adair F, Braun DW Jr (1978) Lobular carcinoma in situ of the breast. Detailed analysis of 99 patients with average follow-up of 24 years. Am J Surg Pathol 2:225-251

22. Bürger H, Simon R, Schäfer KL, Diallo R, Littmann R, Poremba C, van Diest PJ, Dockhorn-Dworniczak B, Böcker W (2000) Genetic relation of lobular carcinoma in situ, ductal carcinoma in situ, and associated invasive carcinoma of the breast. Mol Pathol 53:118-121

23. Morandi L, Marucci G, Foschini MP, Cattani MG, Pession A, Riva C, Eusebi V (2006) Genetic similarities and differences between lobular in situ neoplasia (LN) and invasive lobular carcinoma of the breast. Virchows Arch 449:14-23

24. Aulmann S, Penzel R, Longerich T, Funke B, Schirmacher P, Sinn HP (2008) Clonality of lobular carcinoma in situ (LCIS) and metachronous invasive breast cancer. Breast Cancer Res Treat 107:331-335

25. Bratthauer GL, Tavassoli FA (2002) Lobular intraepithelial neoplasia: previously unexplored aspects assessed in 775 cases and their clinical implications. Virchows Arch 440:134-138

26. Reis-Filho JS, Pinder SE (2007) Non-operative breast pathology: lobular neoplasia. J Clin Pathol 60:1321-1327

27. Perry N, Broeders M, Wolf CD (2006) European guidelines for quality assurance in breast cancer screening and diagnosis. European Commission, Luxembourg

28. Jones JL (2006) Overdiagnosis and overtreatment of breast cancer: progression of ductal carcinoma in situ: the pathological perspective. Breast Cancer Res 8:204

29. Lee S, Medina D, Tsimelzon A, Mohsin SK, Mao S, Wu Y, Allred DC (2007) Alterations of gene expression in the development of early hyperplastic precursors of breast cancer. Am J Pathol 171:252-262

30. Abdel-Fatah TM, Powe DG, Hodi Z, Lee AH, Reis-Filho JS, Ellis IO (2007) High frequency of coexistence of columnar cell lesions, lobular neoplasia, and low grade ductal carcinoma in situ with invasive tubular carcinoma and invasive lobular carcinoma. Am J Surg Pathol 31:417-426 